\title{
Effects of Controlled Atmosphere on the Storage Quality and Aroma Compounds of Lemon Fruits Using the Designed Automatic Control Apparatus
}

\author{
Yuan Ma, ${ }^{1}$ Shaohua Li, ${ }^{1,2}$ Xiaocui Yin, ${ }^{1,3}$ Yage Xing $\mathbb{D},{ }^{1}$ Hongbin Lin, ${ }^{1,4}$ \\ Qinglian Xu $\mathbb{D}^{1}{ }^{1}$ Xiufang Bi, ${ }^{1}$ and Cunkun Chen ${ }^{5}$ \\ ${ }^{1}$ Key Laboratory of Grain and Oil Processing and Food Safety of Sichuan Province, College of Food and Bioengineering, \\ Xihua University, Chengdu 610039, China \\ ${ }^{2}$ Administration for Market Regulation of Weiyuan County, Neijiang 642450, China \\ ${ }^{3}$ Key Laboratory of Food Non-Thermal Processing, Engineering Technology Research Center of Food Non-Thermal Processing, \\ Yibin Xihua University Research Institute, Yibin 644004, China \\ ${ }^{4}$ College of Light Industry and Food Engineering, Sichuan University, Chengdu 610065, China \\ ${ }^{5}$ Key Laboratory of Physiological and Storage of Postharvest Agricultural Products of Agriculture Ministry, National Engineering \\ Technology Research Center for Preservation of Agricultural Products, Tianjin 300384, China
}

Correspondence should be addressed to Yage Xing; xingyage1@163.com

Received 19 November 2018; Revised 12 March 2019; Accepted 13 March 2019; Published 17 June 2019

Academic Editor: Antonio Teixeira

Copyright (C) 2019 Yuan Ma et al. This is an open access article distributed under the Creative Commons Attribution License, which permits unrestricted use, distribution, and reproduction in any medium, provided the original work is properly cited.

\begin{abstract}
'Eureka' lemon fruits were stored under four controlled atmosphere- (CA-) combinations at $8^{\circ} \mathrm{C}$ for 20 days to investigate the effects on weight loss (WL), total soluble solids (TSS), titratable acidity (TA), vitamin C (VC), total phenolic content (TPC), sodium carbonate-soluble pectin (SSP), malondialdehyde (MDA), and volatile compounds. Results showed that the contents of TSS, TA, VC, and SSP in the stored fruits reduced during the storage period, while the WL and MDA increased. Fruit stored under CA2combination $\left(6 \% \mathrm{O}_{2}+8 \% \mathrm{CO}_{2}\right)$ showed the lower contents of WL and MDA and the higher content of TSS, TA, TPC, and VC than that of other treated fruits. The main volatile compounds present in the lemons were terpenoids, aldehydes, alcohols, and esters. In addition, both the terpenoid and aldehyde content are substantially higher in lemons exposed to CA2 conditions. In contrast, the alcohols and esters displayed elevated levels in the regular air (RA) stored fruit. In conclusion, CA with the suitable conditions proves to be better than RA as a storage regimen to keep the quality of lemons. These results indicated that the application of $6 \%$ $\mathrm{O}_{2}+8 \% \mathrm{CO}_{2}$ CA conditions could maintain the quality of 'Eureka' lemon fruit during the storage time of 20 days and should be the optimal storage environment for postharvest Eureka lemons.
\end{abstract}

\section{Introduction}

The lemon fruits used in this study is classified as Citrus limon (L.) Burm. f, which is the third most important Citrus species after orange and mandarin. Lemons contain many high levels of both organic acids and health-promoting phytochemicals such as amines, vitamins, dietary fiber, lavonoids, and limonoids [1-3]. Moreover, citrus fruit is nonclimacteric fruit, with persistently low respiration and ethylene production rates [4]. However, peel pitting and peteca spots can occur on the lemons during storage $[4,5]$. These disorders cause physiological and biochemical changes and eventually lead to fruit quality deterioration, such as VC loss, water loss, and decay during storage and transportation and cause massive commercial revenue losses $[4,5]$. In recent years, the demand to develop appropriate operational techniques has increased significantly [6].

Among alternative treatments, the use of controlled atmosphere (CA) treatment has been extensively researched and the technology is commercially applied to several products, such as litchi fruits [7, 8], pomegranate [6], and apples $[9,10]$. The technique of CA can provide different 
concentrations of gas, such as low $\mathrm{O}_{2}$ and high $\mathrm{CO}_{2}$ levels, which are always used with the appropriate temperature and relative humidity $(\mathrm{RH})$ for fruits storage $[6,7]$. Matityahu et al. (2016) had investigated the quality of different cultivars of pomegranate stored under $\mathrm{CA}\left(2 \mathrm{kPa} \mathrm{O} \mathrm{O}_{2}+5 \mathrm{kPa} \mathrm{CO} \mathrm{CO}_{2}\right)$, wherein fruit quality of husks and aril juice was compared to that of fruit stored in air [6]. They also indicated that CA storage treatment was found to reduce the husk scald and decay development, albeit the RA could better maintain the anthocyanin level and preventing off-flavor development in aril juice [6]. Moreover, as reported by Martins and Resende (2015), the treatments of different CA combinations, such as $1 \% \mathrm{O}_{2}$ and $12 \% \mathrm{CO}_{2}$ and $3 \% \mathrm{O}_{2}$ and $12 \% \mathrm{CO}_{2}$, were found to minimize mass loss and fruit ripening [11]. Increased $\mathrm{CO}_{2}$ concentrations and reduced $\mathrm{O}_{2}$ levels in the storage atmosphere could reduce the respiration rate, delay the senescence, and thus extend the shelf life of fruits and vegetables, but might also induce adverse effects if the levels are either too high or too low [6].

Although MA packages can achieve a beneficial atmosphere at relatively lower cost compared to CA storage, their ability to create and maintain the optimum atmosphere conditions is limited due to the relatively narrow range and characteristic of gas permeability for plastic packaging materials $[15,16]$. In CA storage apparatus, sophisticated mechanisms of $\mathrm{O}_{2}$ removal, $\mathrm{CO}_{2}$ production, and $\mathrm{CO}_{2}$ removal have been applied to control the atmosphere within a narrow target range at optimal storage temperature [15]. The fresh produce container system equipped with a gas diffusion tube can provide an automatically controlled environment with specifically measured $\mathrm{O}_{2}$ and $\mathrm{CO}_{2}$ concentrations and maintain the quality of spinach in a modified atmosphere environment at both constant and varying temperatures [15]. Although CA controlled environments are regularly applied to various fruits and vegetables, limited studies had been reported to employ the automatic CA equipment for keeping the storage quality of lemon fruit.

Therefore, the aim in this works was to investigate the influences of different concentrations of $\mathrm{O}_{2}$ and $\mathrm{CO}_{2}$ on the quality attributes of 'Eureka' lemon fruits using the designed automatic CA control apparatus. First, the intelligent CA apparatus was introduced in order to provide the reference for other researchers. Then, the quality indexes including $\mathrm{WL}$, TSS, TA, VC, TPC, SSP, MDA, and volatile compounds of lemon fruits under four CA combinations at $8^{\circ} \mathrm{C}$ for 20 days were evaluated.

\section{Materials and Methods}

2.1. Materials. Fruits belonging to lemon cv. Eureka were obtained from commercial growers from Anyue, a city in Sichuan province, China. The fruits were immediately transported on paved roads from the collection site to the laboratory in a ventilated vehicle. Sodium hydroxide, oxalic acid, sodium bicarbonate, 2-thiobarbituric acid (TBA), sulphuric acid $\left(\mathrm{H}_{2} \mathrm{SO}_{4}\right)$, absolute ethyl alcohol, trichloroacetic acid (TDA), trans-1,2-diaminocyclohexane$\mathrm{N}, \mathrm{N}, \mathrm{N}^{\prime}, \mathrm{N}^{\prime}$-tetraacetic acid (CDTA), glacial acetic acid, 2,6-dichloroindophenol indophenol sodium salt, and Lascorbic acid were purchased from the Chengdu Kelon Chemical Reagent Factory (Chengdu, China).

2.2. Storage Conditions and Treatments. A total of 240 lemons were divided into four CA treatment groups: $\mathrm{CAl}=4 \% \mathrm{O}_{2}+5$ $\% \mathrm{CO}_{2}, \mathrm{CA} 2=6 \% \mathrm{O}_{2}+8 \% \mathrm{CO}_{2}, \mathrm{CA} 3=8 \% \mathrm{O}_{2}+11 \% \mathrm{CO}_{2}$, and $\mathrm{CA} 4=10 \% \mathrm{O}_{2}+14 \% \mathrm{CO}_{2}$. A random selection of 60 lemons, uniform in size and appearance, were stored in an RA (21\% $\mathrm{O}_{2}+0.03 \% \mathrm{CO}_{2}$ ) environment. Fruits subject to all treatments were stored for 20 days at $8^{\circ} \mathrm{C}$ and $85 \% \sim 90 \%$ RH. Changes in the sample groups were documented every five days. Firstly, for each treatment, three fruits per replicate were peeled. The peel and pulp were immediately frozen with liquid nitrogen, freeze-dried, pulverized, and stored at $-80^{\circ} \mathrm{C}$ until it was subsequently used to determine the TPC. Secondly, the same three fruits in each treatment were used to measure the WL, while four additional fruits were randomly selected to detect the TSS, TA, VC, and MDA content, respectively.

2.3. Determination of WL and TSS. An analytical balance was employed to monitor the individual weight of each lemon during their time in storage. The WL of each lemon was determined by utilizing a method identified by previous research [7]. In addition, the WL was calculated using the following equation and was expressed as a percentage.

$$
\mathrm{W}(\%)=\frac{\mathrm{m}_{\mathrm{i}}-\mathrm{m}_{\mathrm{t}}}{\mathrm{m}_{\mathrm{i}}} \times 100 \%
$$

$\mathrm{W}$ represents the $\mathrm{WL}(\%), \mathrm{m}_{\mathrm{i}}=$ initial fruit weight before storage $(\mathrm{g})$, and $\mathrm{m}_{\mathrm{t}}=$ final fruit weight after storage $(\mathrm{g})$. The TSS were determined by using a method established in a similar study [17] with slight modifications. Lemon juice was extracted with an electric juicer and filtered through four cotton cloths until no juice remained. This process was followed by determining the TSS at an ambient temperature of $25 \pm 1^{\circ} \mathrm{C}$ by using an automatic refraction meter (A610, Hanon Equipment Co., Jinan, China).

2.4. Determination of TA and VC. The TA was determined according to the method described in previous research [18] with slight modifications. Fresh fruit pulp was homogenized in a blender and filtered. A $10 \mathrm{~mL}$ volume of the extracted juice was diluted in distilled water to reach a quantity of $100 \mathrm{~mL}$. The solution was transferred into a $250 \mathrm{~mL}$ beaker and placed over a magnetic stirrer to provide continuous motion to the sample solution. The juice was then titrated using standardized $0.1 \mathrm{~mol} / \mathrm{L} \mathrm{NaOH}$ at the phenolphthalein endpoint $(\mathrm{pH}=8.2 \pm 0.1)$. The TA was expressed as a percentage of the citric acid. The VC was determined by the 2, 6-dichloroindophenol titrimetric method as described in similar research [18]. The fruit pulp was homogenized in a Waring blender and filtered using a muslin cloth. Then, 5 $\mathrm{mL}$ of the clear juice was diluted to $50 \mathrm{~mL}$ using a metphosphoric acid-acetic acid solution. A $7 \mathrm{~mL}$ quantity of this mixture was titrated against a standard indophenol solution. All extractions and titrations were performed in triplicate and the results were expressed in $\mu \mathrm{g}$ ascorbic acid $\mathrm{mL}^{-1}$ pulp juice. 
2.5. Pectin Extraction and Determination. Lemon peel and pulp were extracted using water to reduce the free sugar content before pectin was obtained [19]. Pectin was acquired from the water-extracted peel at optimal conditions of $\mathrm{pH}=1.8$ and $85^{\circ} \mathrm{C}$, for $30 \mathrm{~min}$, and precipitated with isopropanol, according to a method reported in a previous study [20]. Furthermore, the supernatants obtained from the CDTA and $\mathrm{Na}_{2} \mathrm{CO}_{3}$ treatments were combined as SSP [21]. The sample was allowed to decompose entirely in $96 \% \mathrm{H}_{2} \mathrm{SO}_{4}$ containing disodium tetraborate $\left(\mathrm{Na}_{2} \mathrm{~B}_{4} \mathrm{O}_{7} \cdot 10 \mathrm{H}_{2} \mathrm{O}\right)$, followed by transformation into furfural derivatives. These secondary components reacted with the 3-phenylphenol to form a chromogenic product absorption at $530 \mathrm{~nm}$. Galacturonic acid solutions $(10-100 \mu \mathrm{g} / \mathrm{mL})$ were used as a standard calibration curve.

2.6. Determination of TPC. An adapted Folin-Ciocalteu method [18] was used for the determination of the TPC in the lemon peel extracts. A fresh $3.0 \mathrm{~g}$ sample of fruit tissue was homogenized with $30 \mathrm{~mL}$ of $60 \%$ ethanol and centrifuged at $15000 \mathrm{~g}$ for $5 \mathrm{~min}$ at $4^{\circ} \mathrm{C}$. A $10 \mathrm{~mL}$ supernatants were diluted with $40 \mathrm{~mL}$ of $60 \%$ ethanol for the next measurement. A $0.125 \mathrm{~mL}$ quantity of the diluted extract was mixed with $0.625 \mathrm{~mL}$ of distilled water, followed by the addition of 0.125 $\mathrm{mL}$ of Folin-Ciocalteu reagent. After $3 \mathrm{~min}, 1.25 \mathrm{~mL}$ of 7 $\% \mathrm{Na}_{2} \mathrm{CO}_{3}$ and $1 \mathrm{~mL}$ of distilled water were added to the mixture. The solution was allowed a reaction time of $90 \mathrm{~min}$ in a darkened environment, followed by the measurement of the absorbance at $760 \mathrm{~nm}$ employing a spectrophotometer (UV726, T6, PG General, Beijing, China). A standard curve for gallic acid was used to quantify the TPC. The results were expressed as gallic acid equivalents per $\mathrm{kg}$ of fresh weight (FW) $\left(\mathrm{mg} \cdot \mathrm{kg}^{-1}\right)$.

2.7. Determination of MDA. The MDA content was determined according to the method reported by Xing et al. [22] with slight modifications. Tissue $(0.2 \mathrm{~g})$ from the fruit slices were homogenized with $3 \mathrm{~mL}$ of $10 \%$ TDA and centrifuged for $10 \mathrm{~min}$ at $10000 \mathrm{~g}$. This process was followed by mixing $2 \mathrm{~mL}$ of the supernatant with $2 \mathrm{~mL}$ of $6.7 \mathrm{~g} / \mathrm{L}$ TBA (previously dissolved in $10 \%$ ). The obtained reaction solution was heat-treated for $30 \mathrm{~min}$ at $95^{\circ} \mathrm{C}$, rapidly cooled in an ice bath and centrifuged at $10000 \mathrm{~g}$ for $10 \mathrm{~min}$ to clarify the precipitation. The absorbance of the supernatant was measured at $450 \mathrm{~nm}, 532 \mathrm{~nm}$, and $600 \mathrm{~nm}$, respectively, by using a spectrophotometer (UV/VIS756-PC, T6, PG General, Beijing, China). The result was expressed as $\mu \mathrm{mol} / \mathrm{g}$. FW.

$$
\begin{aligned}
& \text { MDA content }(\mu \mathrm{mol} / \mathrm{g} \bullet \mathrm{FW}) \\
& =\frac{\left[6.452 \times\left(\mathrm{OD}_{532}-\mathrm{OD}_{600}\right)-0.559 \times \mathrm{OD}_{450}\right] \times \mathrm{V}_{\mathrm{t}}}{\mathrm{FW} \times \mathrm{V}_{\mathrm{s}}}
\end{aligned}
$$

where $V_{t}$ is volume of the extract solution $(\mathrm{mL}), \mathrm{V}_{\mathrm{s}}$ is volume of the extract solution contained in the reaction mixture solution $(\mathrm{mL})$, and FW is mass of fresh sample (g).

\subsection{Determination of Volatile Compounds by GC-MS}

2.8.1. Volatile Compounds Quantification. A qualitative analysis of the volatile compounds was performed using a GCMS system (Agilent Technologies, Santa Clara, CA, USA) consisting of a gas chromatograph (7890 A) in conjunction with a quadrupole mass spectrometer (MSD $5975 \mathrm{C}$ ), as described by relevant research [23] with slight modifications. Initially, $2 \mathrm{~g}$ of whole fruit pulp was weighed and placed in a 10 $\mathrm{mL}$ vial, followed by the addition of $4 \mathrm{~mL}$ water. The mixture was thoroughly vortexed to ensure homogeneity agitated at $400 \mathrm{rpm}$ and $60^{\circ} \mathrm{C}$ for $30 \mathrm{~min}$ before extraction occurred. Subsequently, a $65 \mu \mathrm{m}$ DVB/PDMS SPME fiber (Supelco, Bellefonte, PA, USA) was exposed to the sorption surface above the liquid level for $10 \mathrm{~min}$ to perform the analyses. The fiber was introduced into the GC injector where desorption was conducted at $250^{\circ} \mathrm{C}$ for $5 \mathrm{~min}$, followed by the initiation and collection of data. An HP-5-MS fused silica capillary column $(30 \mathrm{~m} \times 0.250 \mathrm{~mm}$ inside diameter, $0.25 \mu \mathrm{m}$ film thickness; Agilent, USA) was used to separate the volatiles. The temperature of the injector, GC-MS interface, and ion source was at $250^{\circ} \mathrm{C}, 280^{\circ} \mathrm{C}$, and $230^{\circ} \mathrm{C}$, respectively. Analyses were performed using helium as a carrier gas at a column flow of $1.0 \mathrm{~mL} / \mathrm{min}$, and the electron impact ionization was $70 \mathrm{eV}$. The following oven temperature program was used: the initial temperature of $40^{\circ} \mathrm{C}$ was incrementally increased by $3^{\circ} \mathrm{C} \min ^{-1}$ to $150^{\circ} \mathrm{C}$, followed by progressive temperature augmentation of $5^{\circ} \mathrm{C} \min ^{-1}$ to $300^{\circ} \mathrm{C}$, where it was maintained for $3 \mathrm{~min}$. The data was collected at a scanning range of 35-350. The analytical process to obtain the volatile compounds from the lemons was repeated three times. The proportion of each compound was estimated dividing its mean area by the total area of the chromatogram and expressed as percentages.

2.8.2. Volatile Compound Identification. The volatile compounds were identified by a GC-MS QP2010plus (Shimadzu Corporation, Kyoto, Japan), as described by Wang et al. [24] with some modifications to the method. Initially, $2 \mathrm{~g}$ of lemon peel (previously thawed at ambient temperature), $1 \mathrm{~g}$ of $\mathrm{NaCl}$, and $1 \mu \mathrm{L}$ of cyclohexanone standard solution $(0.95 \mathrm{mg})$ were transferred to a SPME extraction bottle $(20 \mathrm{~mL})$ and preheated in a water bath at $40^{\circ} \mathrm{C}$ for $15 \mathrm{~min}$ before the extraction process occurred. Subsequently, a DVB/CAR/PDMS fiber (Supelco, $50 / 30 \mu \mathrm{m} \times 20 \mathrm{~mm}$ ) was exposed to the headspace above the liquid surface for $45 \mathrm{~min}$ at $40^{\circ} \mathrm{C}$. To quantify the volatile compounds, the same described GC and MS chromatographic conditions were adopted. The mass spectra of each compound were compared with those available in the National Institute of Standards and Technology (NIST) library and by comparing the linear retention index (LRI) with those available in existing scientific literature.

2.9. Statistical Analyses. The experimental data were analyzed by SPSS/PC version 23.0 (SPSS Inc., Chicago, USA) with oneway analysis of variance (ANOVA) and principal component analysis (PCA). The results were reported as the mean $\pm \mathrm{SD}$ and the differences were recognized as significant $(p<0.05)$. 


\section{Results and Discussion}

3.1. Design Introduction of the Intelligent CA Apparatus. The CA equipment plays the crucial role for the storage of postharvested agriculture products. However, only few works were carried out on the improvement and design of the CA apparatus. In this study, the working principle and process of $\mathrm{CA}$ equipment used in this investigation are introduced in detail, as shown in Figures $1(\mathrm{a})-1(\mathrm{c})$, which might provide the reference for other researchers to develop the upgraded version of similar apparatus and for the investigation on the storage quality of other fresh fruits and vegetables. The configuration and control charts of CA equipment used in this work are provided and shown in Figures 1(a)-1(c). The model of an intelligent CA device used an automatic control system based on a Programmable Logic Controller (PLC). This device could detect and analyze the concentration of carbon dioxide and oxygen in the air, to regulate the gas composition within the CA chamber. As shown in Figure 1(a), the nitrogen in the air was modified to more than $99.5 \%$ purity through an air compressor before it entered the CA chamber. Moreover, $99.9 \%$ pure carbon dioxide was introduced to the chamber, followed by the addition of oxygen after purification and moisture removal. Subsequently, the automatic program was initialized to control the gas composition of oxygen and carbon dioxide to achieve the desired parameters (Figure 1(a)). Therefore, this device was successful in automatically removing the ethylene and controlling the $\mathrm{RH}$.

As shown in Figure 1(b), the control chart consisted of six parts, including the sensors, the analog module, the PLC, the valve assembly, the relay, and six machines. The sensors comprise the nitrogen sensor, the oxygen sensor, the carbon dioxide sensor, the ethylene sensor, the temperature sensor, and the humidity sensor. Furthermore, the six machines refer to the nitrogen generator, the oxygenator, the humidifier, the ozone sterilizer, the $\mathrm{CO}_{2}$ source, and the ethylene removal machine. In this study, the lemon fruits were stored in a CA environment within $48 \mathrm{~h}$ of harvest, and both the $\mathrm{CO}_{2}$ and $\mathrm{N}_{2}$ in the CA chamber were obtained from the air compressor and membrane generator. The gas composition of the storage chamber was analyzed at $10 \mathrm{~min}$ intervals and adjusted when necessary. Generally, the level of $\mathrm{O}_{2}$ fluctuated between $4 \%$ and $10 \%$, while the $\mathrm{CO}_{2}$ level was between $5 \%$ and $14 \%$, and that of $\mathrm{RH}$ was between $80 \%$ and $95 \%$. Moreover, the CA storage regimes ranged from $5 \mathrm{~d}$ to $20 \mathrm{~d}$. As shown in Figure 1(c), four CA chambers with a volume of $1 \mathrm{~m}^{3}$ were used to store the lemons and kept closed. A sensor was installed into each CA chamber to monitor the respective concentrations of $\mathrm{O}_{2}$ and $\mathrm{CO}_{2}$.

3.2. The Effects of CA and RA on the WL, TSS, and TA of the Lemons. During the storage, the effect of CA and RA on the WL, TSS, and TA of the lemons was monitored (Figures $2(a)-2(c))$. The WL index of the lemons exhibited rising tendencies with prolonged storage time (Figure 2(a)). The differences in the results obtained from the RA conditions were significant from day ten of the storage to the end of the experiment. At the conclusion of the storage time, the
WL of fruit subject to RA, CA1, CA2, CA3, and CA4 were $3.52 \%, 2.84 \%, 2.14 \%, 2.27 \%$, and $2.49 \%$, respectively. Exposing lemons to $\mathrm{CA}$ conditions significantly reduced the WL index. Moreover, $\mathrm{CA} 2$ with $6 \% \mathrm{O}_{2}+8 \% \mathrm{CO}_{2}$ exhibited a substantially lower WL index compared to other treatments (Figure 2(a)). On the one hand, the WL of all the samples increased with time, which was due to the matter consuming. Similar result was also found by other researchers. As reported by Ali et al. [7], fruit weight loss increased gradually with the extension of storage time. Moreover, according to the investigation of Selcuk and Erkan [25], the WL of 'Istanbul' medlar fruit under modified and palliflex controlled atmosphere storage progressively increased with storage time and was linear for all treatments. On the other hand, the results obtained in this investigation also indicated that CA could maintain the weight of lemons more effectively than RA. Similar results were previously reported by some researchers [7, 25]. Selcuk and Erkan [25] reported that the WL of medlar fruit stored in MAP and CA was lower than that of an RA-stored sample. Ali et al. [7] also found that, among different CA combinations, litchi fruit stored under $1 \% \mathrm{O}_{2}+5 \% \mathrm{CO}_{2}$ maintained substantially about 2.71-fold less weight loss during 35 days of storage [10]. Ali et al. [7] and Mendya et al. [26] demonstrated that the water is the main component found in fruits and vegetables, and the reduction of its loss from the commodity is the most critical requirement for maintenance of postharvest quality attributes. Moreover, the water loss of more than 4-6\% (of the total fresh weight) results in visible wilting or wrinkling of the surface of most commodities $[27,28]$. Respiration and transpiration are the main causes of weight loss in stored fruit and vegetables, which might induce the matter consuming $[29,30]$. This is because that the stomata transpiration and direct evaporation through epidermal cell might induce the migration of the water from the fruit to the surrounding environment [31]. More importantly, weight loss was also significantly affected by storage conditions [16]. The low temperature, low content of $\mathrm{O}_{2}$, and high content of $\mathrm{CO}_{2}$ effectively inhibit the water migration and keep the final quality of stored fruits. As reported by Zhang et al. [32], the higher content of free water at strawberries cores retained better quality during storage. The weight loss of the control Ottomanit figs was extremely high, even though $\mathrm{RH}$ in the cold room was above $90 \%$, probably reflecting the effects of advanced ripening and spoilage [7]. The reason for lower weight loss in CA-stored fruit can also be attributed to the slower ripening rate and respiration rate [33]. The suitable concentrations of $\mathrm{O}_{2}$ and $\mathrm{CO}_{2}$ in $\mathrm{CA}$ system might maintain the internal atmosphere of the fruit and are beneficial to the storage of lemon and have a greater effect on prolonging its storage period. Further studies focusing on the water migration, softening, and respiration rate of lemon during storage are necessary to investigate.

To further study the impact of storage conditions on the quality of lemons, the parameters commonly used to evaluate taste were measured, i.e., TA and TSS. As shown in Figure 2(b), when the storage time was increased, the TSS in fresh lemons displayed a decline in all relevant samples. At the end of the storage period, the lemons that were 




(a)



(b)



(c)

FIGURE 1: Layout diagram (a), control diagram (b) and experimental apparatus (c) of modified atmosphere controlled test box. ((a) where 1, 7, 16, 23: extracting ethylene; 2, 8: backing to gas; 3, 9: $\mathrm{N}_{2}+\mathrm{O}_{2}+\mathrm{CO}_{2} ; 4$, 10: ozone; 5, 11, 14, 21: taking out the gas; 13, 20: exhausting gas; 15 , 22: recovering gas; 17, 24: removing ethylene loop; 18: sensing components and pump; 19: machine of ethylene removal; (a) where 1: Temperature sensor; 2: oxygen sensor; 3: carbon dioxide sensor; 4: nitrogen sensor; 5: ethylene sensor; 6: humidity sensor; 7: analog module; 8: touch screen; 9: program mablelogic controller (PLC); 10: valve assembly; 11: nitrogen generator; 12: oxygen generator; 13: humidifier; 14: ozone sterilization machine; 15: $\mathrm{CO}_{2}$ gas source; 16: ethylene removal machine; 17: relay). 


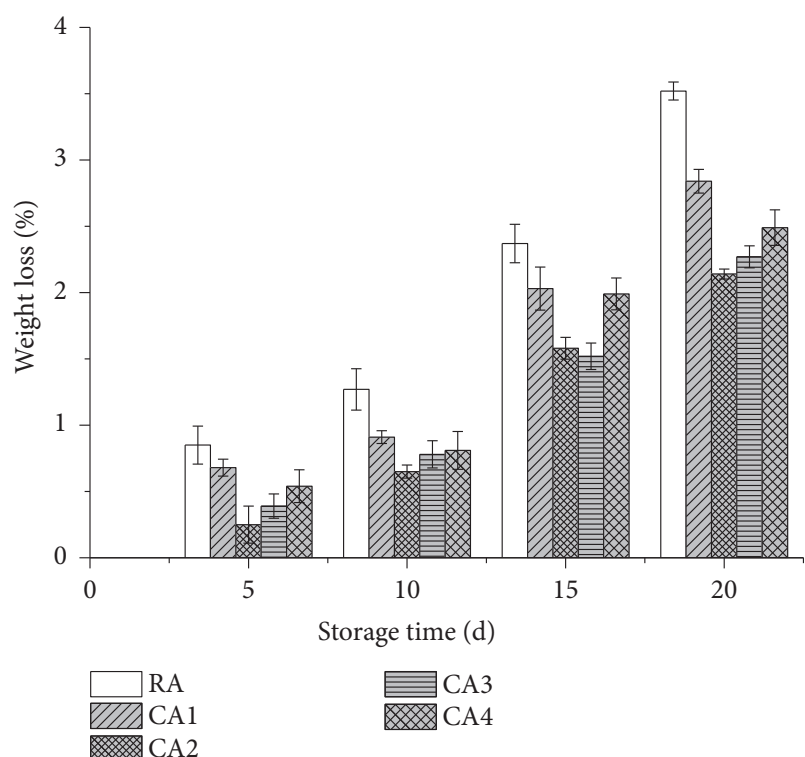

(a)

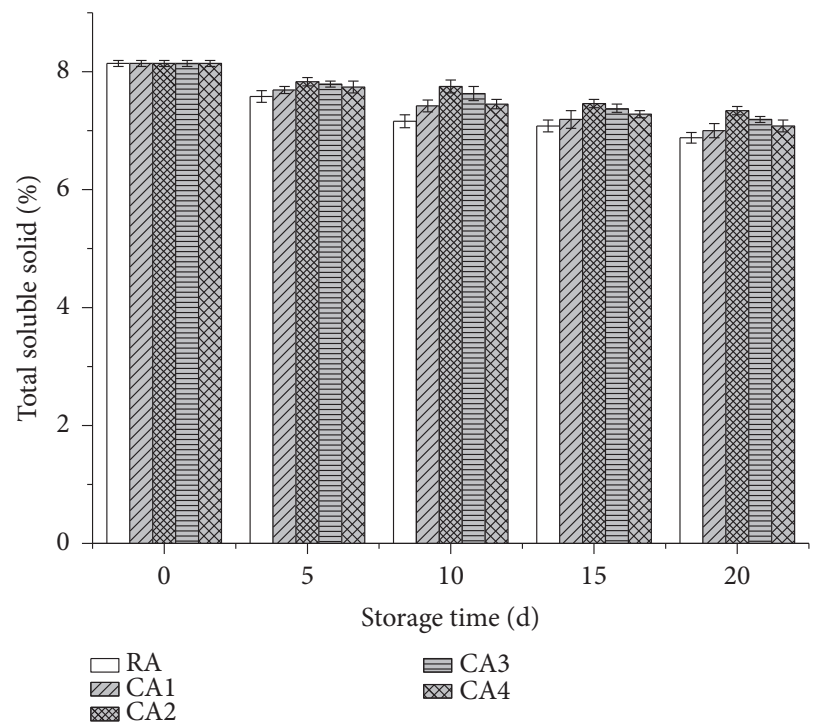

(b)

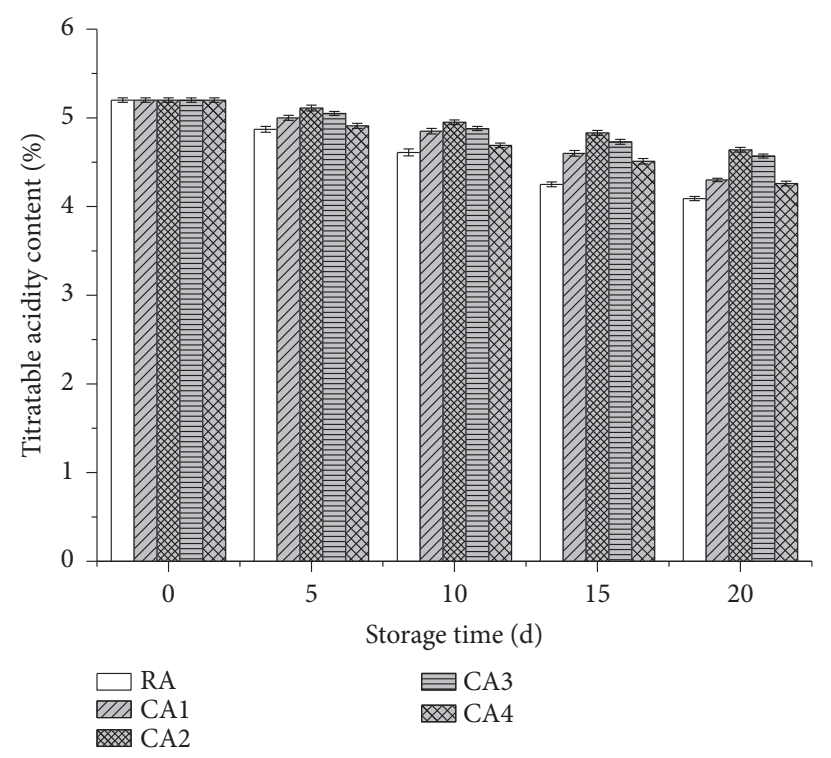

(c)

Figure 2: Effects of CA and RA on the WL, TSS and TA of lemons during 20 days' storage.

subject to a CA environment exhibited significantly higher TSS content than that in the RA-stored fruit. Additionally, the TSS in fruit treated with RA, CA1, CA2, CA3, and CA4 were $6.88 \%, 7.00 \%, 7.34 \%, 7.19 \%$, and $7.08 \%$, respectively, while the marked retention of the TSS was obtained under the CA2 treatment at $6 \% \mathrm{O}_{2}+8 \% \mathrm{CO}_{2}$. Similarly, Ali et al. [7] found that the soluble solid content (SSC) in litchi fruit continuously decreased during a 35-day storage period regardless of the treatment applied, while the highest retention level of the SSC was obtained during the $\mathrm{CA}$ treatment at $1 \% \mathrm{O}_{2}+5 \% \mathrm{CO}_{2}$. In addition, similar results were obtained by Tian et al. [8], who reported the SSC decreased with prolonged storage time, and the CA was more effective than MAP (modified atmosphere packing) and
RA treatments in maintaining the SSC of the fruits. Thus the CA-stored fruits maintained a higher TSS content that might be attributed to the suppressed senescence caused by the CA treatment $[34,35]$. Furthermore, CA treatment could reduce the metabolic activity of the fruits that retarded the polysaccharide degradation reactions [36]. The CA consisting of reduced $\mathrm{O}_{2}$ and elevated $\mathrm{CO}_{2}$ concentrations inhibited the respiration rate and sugar depletion in the samples, thus maintaining the higher TSS level than RA treatment [6].

TA is commonly used to demonstrate the ripening stage of the fruits as well as evaluate the fruit taste which is represented mainly by the balance between sweetness and acidity [35]. The data analysis showed that the TA of fresh lemon juice decreased with prolonged storage time in all 


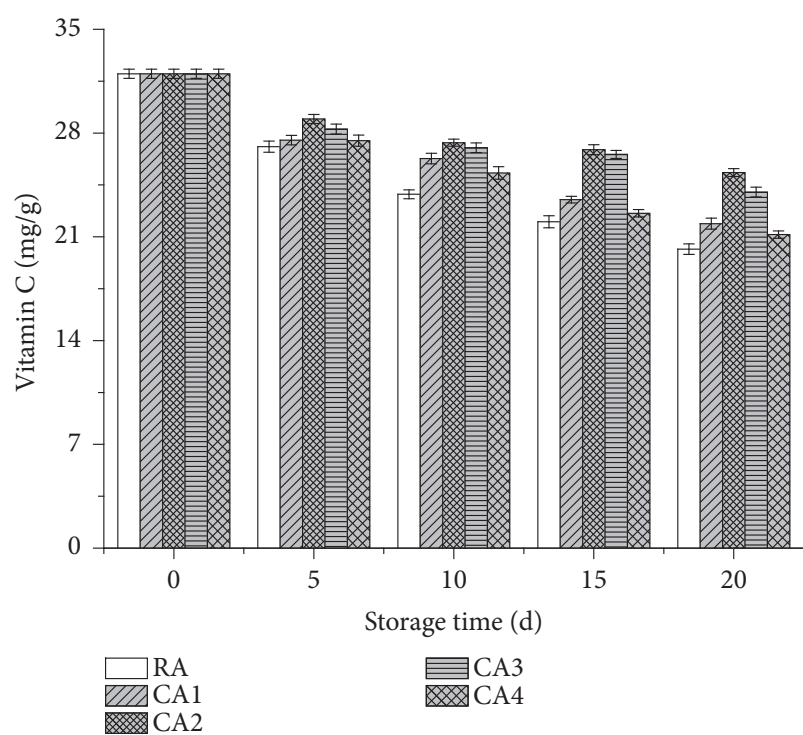

(a)

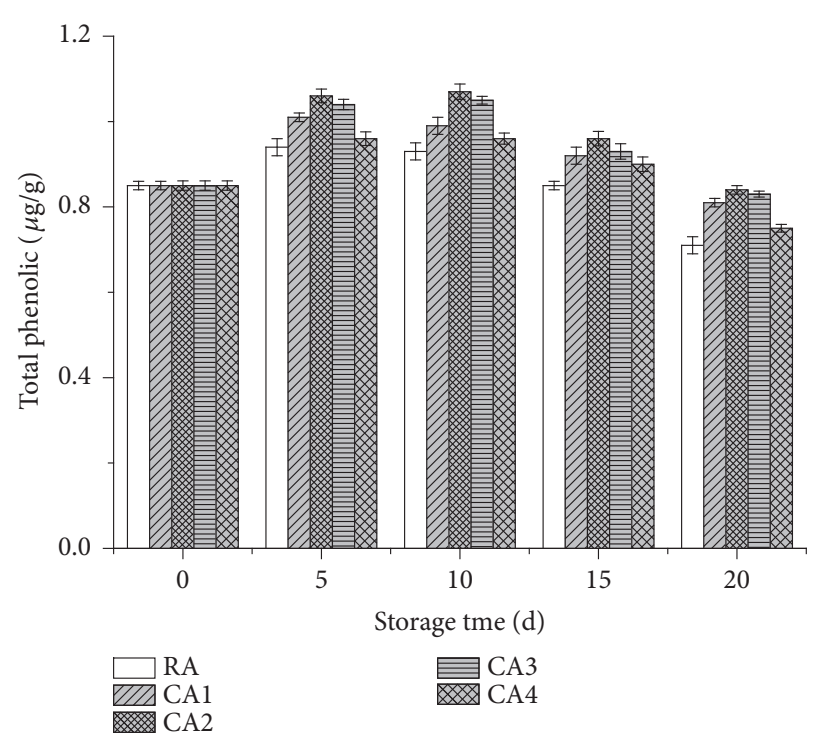

(b)

FIGURE 3: Effects of CA and RA on the VC and TPC of lemons during 20 days' storage.

stored samples (Figure 2(c)). At the end of the storage period, the lemons subject to a CA environment exhibited higher TA content than that of the RA-stored fruit. The TA of fruit treated with RA, CA1, CA2, CA3, and CA4 were at 4.09 $\%, 4.30 \%, 4.64 \%, 4.57 \%$, and $4.26 \%$, respectively, while the marked retention of the TA was obtained from the CA2 treatment at $6 \% \mathrm{O}_{2}+8 \% \mathrm{CO}_{2}$ (Figure 2(c)). Similarly, Ali et al. [7] found that the TA levels in litchi fruit significantly decreased during storage. Additionally, the fruit subject to $1 \% \mathrm{O}_{2}+5 \% \mathrm{CO}_{2} \mathrm{CA}$ conditions maintained the highest TA content at the end of the experiment. Matityahu et al. [6] also reported the TA in pomegranates declined during storage. The reason for high TA in CA-stored fruit could also be attributed to the slower ripening rate and reduced respiration rate [27]. The concentration of $\mathrm{O}_{2}$ and $\mathrm{CO}_{2}$ played the crucial role in inducing the slower ripening rate of pear samples [37]. This result might also be due to the reduced decarboxylation of organic acids including citric acid and malic acid in fruit exposed to low $\mathrm{O}_{2}$ and high $\mathrm{CO}_{2}$ levels during storage [38], which are always used as the substrates for the enzymatic reactions of respiration [39]. The decrease of TA is also associated with cellular activity, in which organic acids serve as substrates that enter the Krebs cycle to gain energy for repairing the aging cells and membranes [40].

\subsection{Effects of CA and RA on VC and TPC Levels in Lemons} during Storage. Results regarding the impact of CA and RA conditions on VC and TPC levels are shown in Figures 3(a) and 3(b). As shown in Figure 3(a), during the period of storage, the VC content of the lemons gradually decreased irrespective of the treatments. However, averaged over the control, CA-stored fruit showed significantly higher VC content during the 20-day storage period. At the end of the storage time, the lemons subject to CA maintained higher $\mathrm{VC}$ content than that in the RA-stored fruit. The VC content of the fruit treated with RA, CA1, CA2, CA3, and CA4 were $20.17,21.89,25.34,24.02$, and $21.15 \mathrm{mg} / \mathrm{g}$, respectively, while the marked retention of the $\mathrm{VC}$ was obtained during CA2 treatment at $6 \% \mathrm{O}_{2}+8 \% \mathrm{CO}_{2}$ (Figure 3(a)). Similarly, studies performed by Selcuk and Erkan [25] suggested that a decreasing trend was present in the ascorbic acid levels of all stored medlar fruit throughout the 60-day storage period. Tian et al. [41] also found that the VC content of sweet cherries decreased with prolonged storage time and fruits subject to $5 \% \mathrm{O}_{2}+10 \% \mathrm{CO}_{2}$ showed higher $\mathrm{VC}$ content than that in the MAP-stored and $70 \% \mathrm{O}_{2}+0 \% \mathrm{CO}_{2}$ stored samples after 60 days of storage. The decrease of ascorbic acid under prolonged storage conditions might be due to the utilization of different organic acids during fruit respiration or their likely conversion to the sugars [7]. Higher retention of $\mathrm{VC}$ was observed in litchi fruit kept at $\mathrm{CA}_{1}\left(3 \% \mathrm{O}_{2}+7 \%\right.$ $\left.\mathrm{CO}_{2}\right)$ than the fruit in $\mathrm{CA}_{2}\left(17 \% \mathrm{O}_{2}+6 \% \mathrm{CO}_{2}\right)$, and this was attributed to reduced enzymatic oxidation in an environment presenting low $\mathrm{O}_{2}$ and high $\mathrm{CO}_{2}$ conditions [33]. The ascorbic acid content reduced with advancement in fruit maturity, and the CA-stored samples exhibited higher retention of VC during 20 days storage period than the fruit in RA. However, this result might be attributed to the inhibited respiration rate and the reduced oxidation of various organic acids $[7,10]$.

The health benefits of lemons are related, at least in part, to its TPC. As shown in Figure 3(b), the TPC of the lemons increased in all treated samples during the first 5 days, followed by a gradual decrease over a prolonged storage period. On day 20, the lemons stored in CA maintained higher TPC than the RA-stored fruit. The TPC of fruit treated with RA, CA1, CA2, CA3, and CA4 were $0.71,0.81,0.84,0.83$, and $0.75 \mu \mathrm{g} / \mathrm{g}$, respectively, while the marked retention of the TPC was obtained during the CA2 treatment at $6 \% \mathrm{O}_{2}+$ $8 \% \mathrm{CO}_{2}$ (Figure 3(b)). Similarly, Ali et al. [7] found that the TPC was significantly decreased during a 35-day storage 


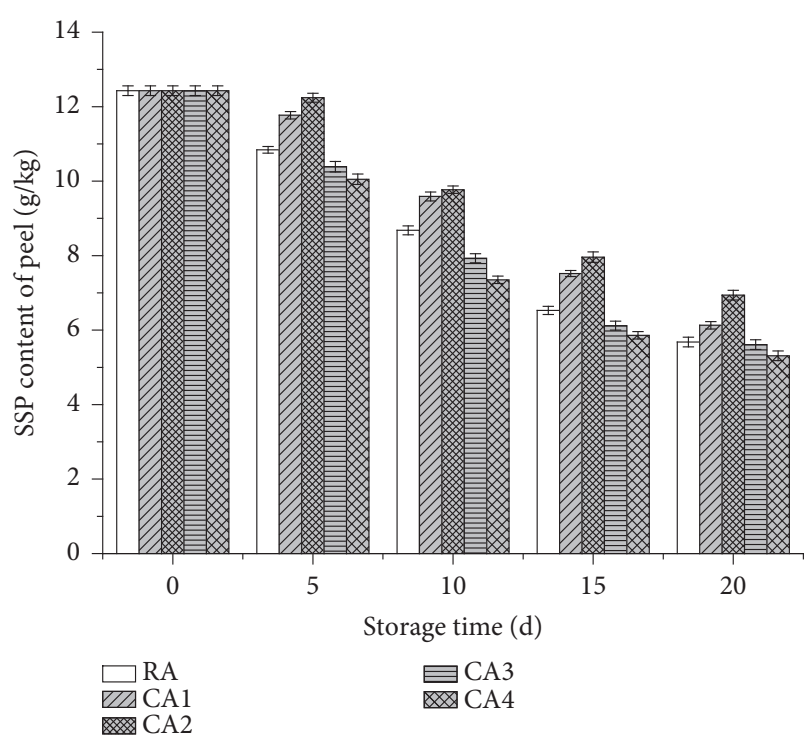

(a)



(b)

FIGURE 4: Effects of CA and RA on the SSP content of lemon peel and pulp during 20 days' storage.

period of litchi fruit. On day 35, the fruit subject to $1 \% \mathrm{O}_{2}$ $+5 \% \mathrm{CO}_{2} \mathrm{CA}$ conditions maintained the highest TPC level. Tian et al. [8] also found that the TPC of litchi fruits stored under CA conditions decreased to 42.0-43.8 $\mu \mathrm{g} / \mathrm{g}$ after 14 days. The reduction of TPC in stored lemon fruits can be attributed to the change in enzyme activity and the removal of astringency during the ripen process resulting in phenolic degradation $[25,42]$. The high TPC level in the CA-stored samples might be due to the result of inhibited oxidation and decreased membrane leakage. The impaired membrane integrity ultimately might induce the peroxidase (POD) and polyphenol oxidase (PPO) to combine with the content [7].

3.4. The Effects of CA and RA on the SSP Content of Lemons during Storage. The changes to the cell wall structures, especially pectin components are mostly correlated with the textural softening of fruit [29]. The SSP content in the lemon peel tissue gradually decreased with prolonged storage time irrespective of which treatments were applied (Figure 4(a)). On day 20, the SSP in the lemon peel treated with RA, $\mathrm{CA} 1, \mathrm{CA} 2, \mathrm{CA} 3$, and CA4 were 5.68, 6.13, 6.94, 5.61, and $5.31 \mathrm{~g} / \mathrm{kg}$, respectively, while the marked retention of the SSP was obtained during the CA2 treatment at $6 \% \mathrm{O}_{2}+8$ $\% \mathrm{CO}_{2}$. Considering the SSP content of the pulp, a similar trend was observed, where a gradual decrease was evident in conjunction with an extended storage period (Figure 4(b)). Therefore, after 20 days of storage, the SSP in the lemon pulp treated with RA, CA1, CA2, CA3, and CA4 were 1.70, $1.83,1.93,1.54$, and $1.47 \mathrm{~g} / \mathrm{kg}$, respectively, while the marked retention of the SSP in lemon pulp was obtained during the CA2 treatment at $6 \% \mathrm{O}_{2}+8 \% \mathrm{CO}_{2}$ (Figure $4(\mathrm{~b})$ ).

Results indicated that the SSP content in the lemon peel tissue of all the samples decreased with prolonged storage time. This might be due to the change of water-insoluble protopectins into water-soluble pectins during the storage period, which could also induce the loss of fruit firmness [33, 43]. As demonstrated by Yang et al. [43], in the early storage time, the pectin consisted of linear single fractions, long chains, branch structure, short chains, and polymers might not be depolymerized by those pectinolytic enzymes $[29,43]$. Furthermore, with extending the storage time, the degradation of pectin chain widths occurred, which was a natural senescence process of fruits as pectinolytic enzymes in fruits continued to degrade pectin $[43,44]$. As indicated by Liu et al. [45], a larger number of branched structures and fractions with multiple branching structures were found in the untreated samples. Net-like structures were no longer observed at the end of storage [43]. On the other hand, the highest retention of the SSP was observed in the samples with CA2 treatment $\left(6 \% \mathrm{O}_{2}+8 \% \mathrm{CO}_{2}\right)$. Similar results were obtained by previous studies [46, 47]. Yang et al. [46] found that the gradual degradation of SSP was observed in yellow peaches when exposed to prolonged storage time under CA conditions. Huyskens-Keil et al. [47] reported that after a 21-day storage period, the insoluble pectin content in mature Pepino fruits decreased, while the levels of watersoluble pectin (WSP) was partially prevented from increasing by the continuous and varying CA treatments. The reduction of pectin might be associated with various enzyme activities, such as pectin-methylesterase and polygalacturonase [47]. High $\mathrm{CO}_{2}$ concentrations were helpful in reducing softening in ripe Pepinos; this result could mainly be ascribed to the inhibition of the conversion of protopectin to soluble pectin by the suppression of degrading cell wall enzyme activity [47]. CA conditions can impede the degradation of the connections between chelate-soluble pectin molecules (CSP), causing a higher retention level of pectin as evident from the CA1 $\left(2 \% \mathrm{O}_{2}+10 \% \mathrm{CO}_{2}\right)$ and CA2 $\left(5 \% \mathrm{O}_{2}+5 \%\right.$ $\mathrm{CO}_{2}$ ) treatments [48]. The fruit subject to CA2 treatment at $6 \% \mathrm{O}_{2}+8 \% \mathrm{CO}_{2}$ showed higher level of SSP that might 




Figure 5: Effects of CA and RA on the MDA content of lemons during 20 days' storage.

be the result of the degradation of SSP molecules that were inhibited by concentrations containing lower $\mathrm{O}_{2}$ and higher $\mathrm{CO}_{2}$ levels [46]. The suitable CA treatment could inhibit the degradation of pectin chains by inhibiting the respiration and metabolism rate of fruits, thus reducing the activity of pectin degrading enzyme [30]. Moreover, the SSP chain width and nanostructural morphologies could also influence the fruit firmness [30]. On the other hand, the different CA conditions might also affect the solubilisation and depolymerization processes of CSP and the depolymerized and degraded processes of WSP side chains during fruit softening [44]. These functions could also induce the network structure of pectin [43]. However, the relationship between the changes in SSP content, the firmness of fruits during storage, the optional parameters, and technologies is still unclear and should be also considered. More importantly, the influencing mechanism of CA conditions on the pectin degradation in lemon fruits is also important. Further research works are necessarily conducted in order to understand these issues.

3.5. The Effects of CA and RA on the MDA in Lemons during Storage. MDA is the product of lipid peroxidation and is often used as direct indicators of membrane injury and cellular oxidative damage [22]. As shown in Figure 5, the continuously growing trends of MDA content were observed both in control and CA treated lemon fruit. On day 20, the MDA contents in lemon fruit treated with RA, CA1, CA2, CA3, and CA4 were $0.78,0.73,0.61,0.67$, and 0.88 $\mu \mathrm{mol} / \mathrm{g}$, respectively. Additionally, the fruit that were subject to CA2 $\left(6 \% \mathrm{O}_{2}+8 \% \mathrm{CO}_{2}\right)$ conditions displayed a lower MDA $(0.61 \mu \mathrm{mol} / \mathrm{g})$ content than those exposed to other storage conditions. This result was $0.17 \mu \mathrm{mol} / \mathrm{g}$ lower than that obtained from the RA-stored sample. Given the various $\mathrm{CA}$ combinations, fruit stored in CA2 conditions exhibited a substantially lower MDA content during a 20-day storage period.

Similar results were previously reported by some researchers [7, 10]. Ali et al. [7] reported that the MDA content in all stored litchi fruit samples increased during a 35 -day storage period. However, the fruits kept in $1 \% \mathrm{O}_{2}$ $+5 \% \mathrm{CO}_{2}$ conditions displayed a lower MDA content $(60$ \%) than the samples subject to other treatments. Studies performed by Mditshwa et al. [10] suggested that the MDA content in all stored apples (cv. Granny Smith) increased with prolonged storage time, which was caused by elevated lipid peroxidation. These results indicated that the MDA content is a significant lipid peroxidized product, which reflects the actual extent of membrane-lipid-peroxidation induced by reactive oxygen species (ROS) [7, 22]. Increased production of ROS leads to enhanced lipid peroxidation, causing membrane deterioration [7]. The lower MDA production in CA1, CA2, and CA3 stored fruit can be attributed to reduced ROS accumulation, therefore, inhibiting membrane peroxidation [7]. However, the CA4-stored sample had higher MDA content than those subject to other CA treatments. This might be associated with the high oxygen atmospheres that promote a higher level of lipid oxidation [49].

3.6. Multivariate Analysis-PCA. A PCA was conducted to obtain a broader view of the biochemical changes taking place in CA and RA-stored fruit. PCA scores and loadings are shown in Figure 6. Clear separation was observed demonstrating the effects of the storage conditions on the volatile components in Eureka lemons. The first three results account for $84.07 \%(\mathrm{~F} 1=45.95 \%$; F2 $=24.03 \%$; F3=14.09 $\%)$ of the total variance and clearly separated fruit stored in CA and RA environments, exhibiting two distinct clusters. Figure 6(a) (scores plot) shows that the CA1 treated group had similar properties to the CA2 group, and the CA3 treated group had similar properties to the CA4 group. However, the control (CK) group had distinct properties from the other groups. Figure 6(b) (loading graph) provides a comprehensive view of the relationships among the volatiles measured in this experiment. According to Liu et al. [50], the classification of factor loadings is considered strong, moderate, and weak when corresponding to loading values of $0.75,0.75-0.50$, and $0.50-0.30$, respectively. As shown in Figure 6(a), all volatile components were positively correlated with PC1 (45.95\%). Therefore, the scores can be interpreted by factor loadings, with $\mathrm{PC} 1$ positively associated with terpenoids. Consequently, terpenoids have a greater impact on the volatile components of lemons. Terpinolene, (Z)$\alpha$-Bergamotene, $\beta$-Santalene, $\beta$-Caryophllene, Citronellal, Decanal, and Geranyl-propionate were considered as the main volatile compounds in lemons.

\subsection{The Effects of $C A$ and $R A$ on the Aroma Compound} Analysis of Lemons during Storage. A total of 40 volatile compounds were identified by the GC/MS in RA, and CAstored lemons, and were grouped according to the following chemical classes (Table 1): terpenoids (20 compounds 


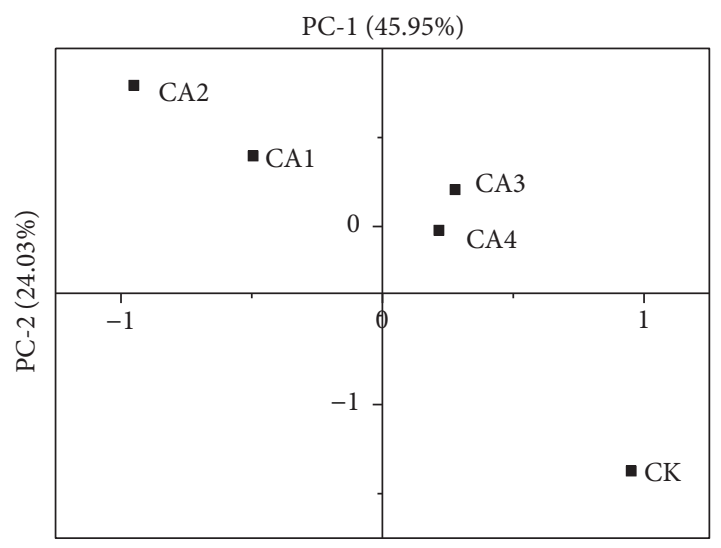

(a1)

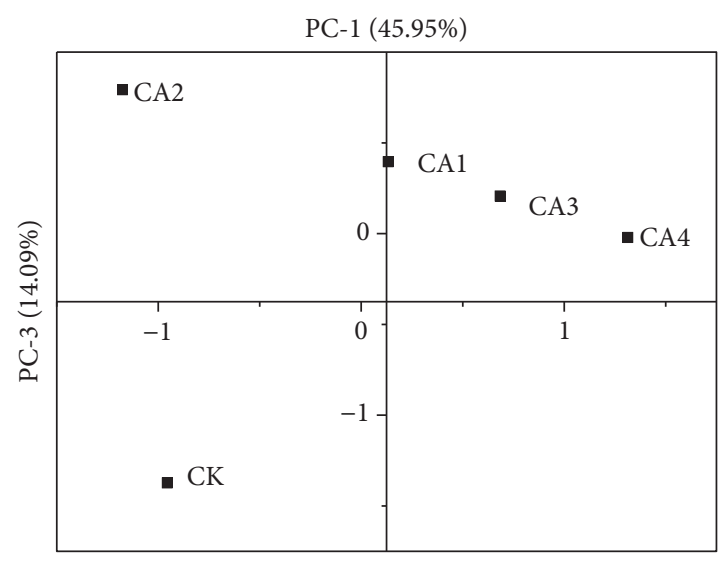

(a2)

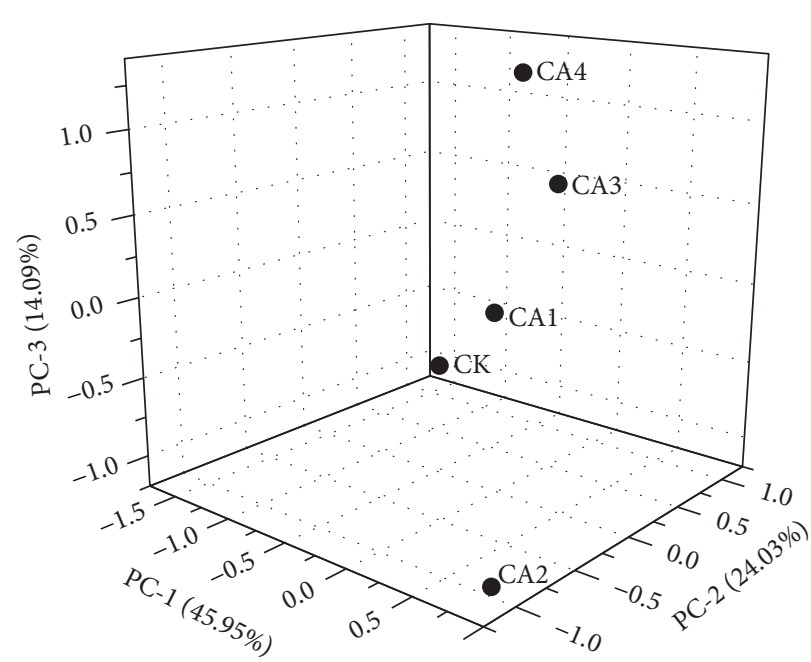

(a3)

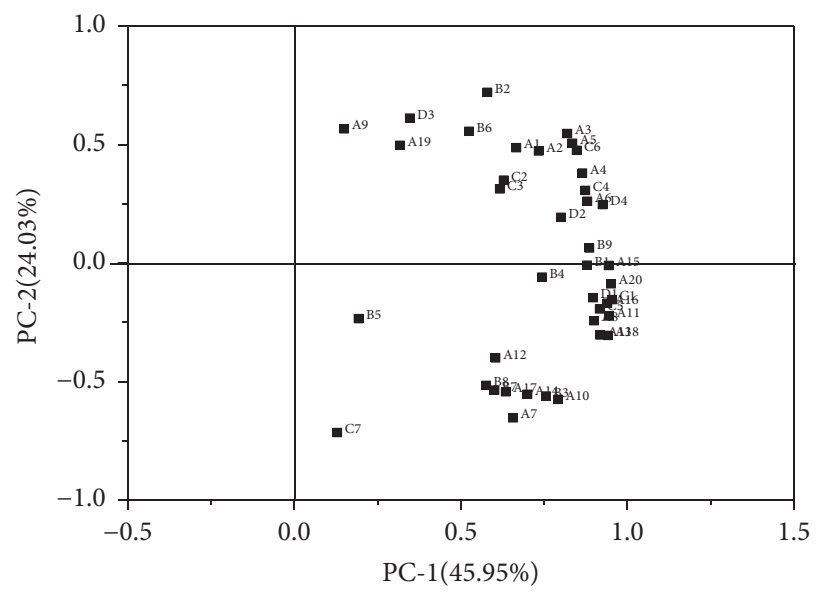

(b1)

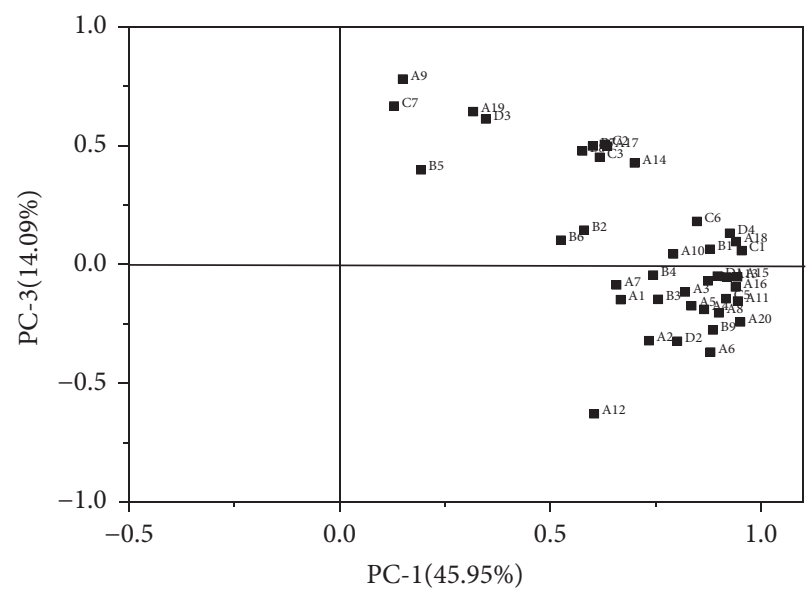

(b2)



(b3)

(b)

Figure 6: Principal component analysis (along PC-land PC-2, PC-1, and PC-3) of the volatile profile of lemon fruit stored under control $(\mathrm{CK})$, and different controlled atmosphere (CA) environments ( $\mathrm{CAl}=4 \% \mathrm{O}_{2}+5 \% \mathrm{CO}_{2}, \mathrm{CA} 2=6 \% \mathrm{O}_{2}+8 \% \mathrm{CO}_{2}, \mathrm{CA}_{3}=8 \% \mathrm{O}_{2}+11 \% \mathrm{CO}_{2}$, and $\mathrm{CA} 4=10 \% \mathrm{O}_{2}+14 \% \mathrm{CO}_{2}$ ) after 20 days of storage. (a) Scores plot; (b) loadings plot. 


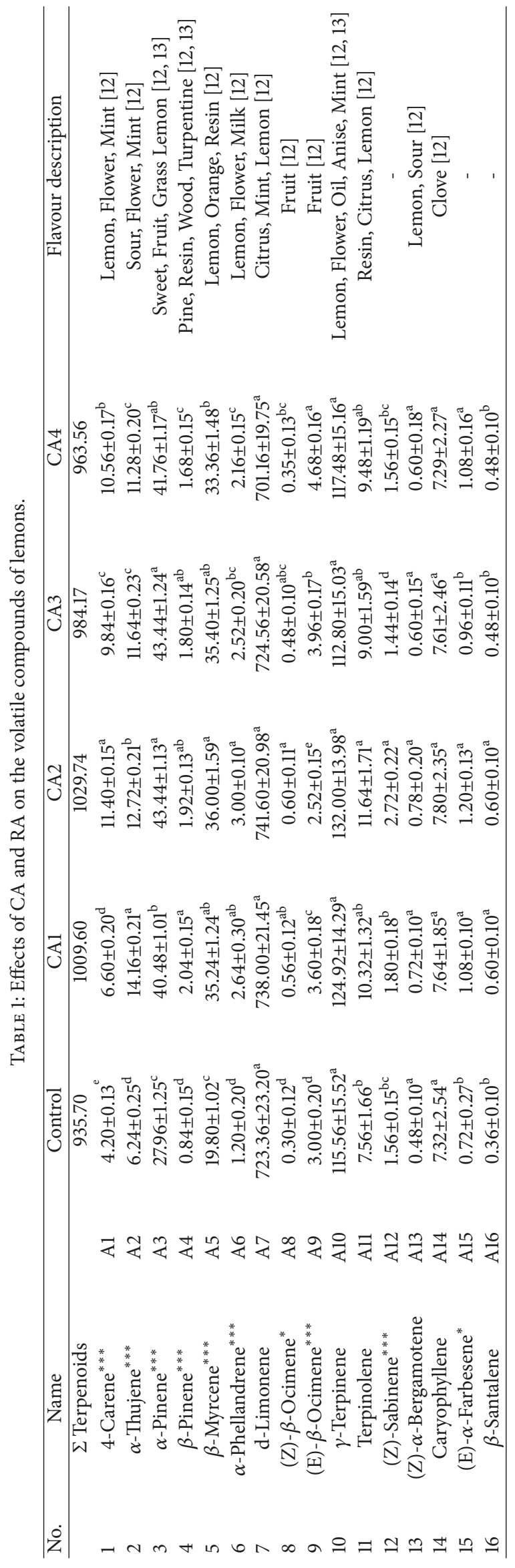




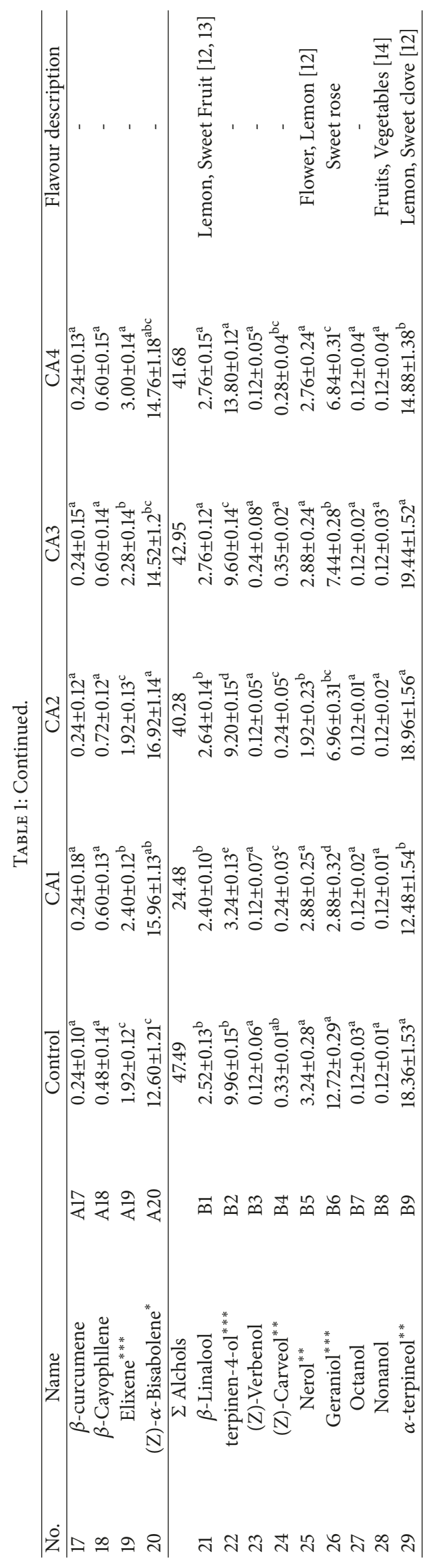




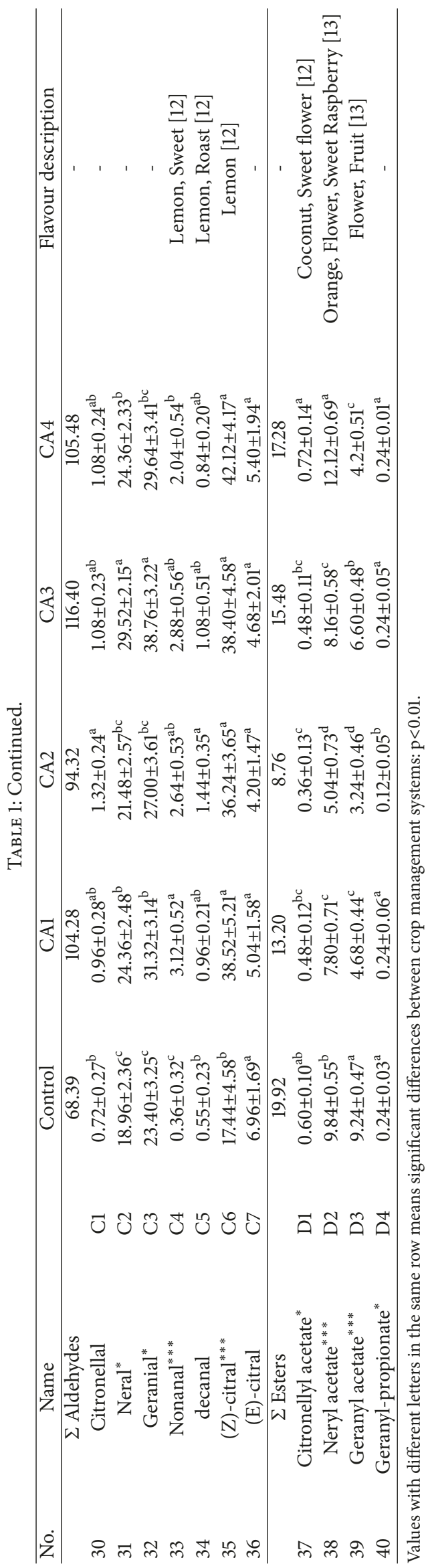


identified), alcohols (9), esters (4), and aldehydes (7). These components were detected in all samples following the conclusion of the storage period, regardless of the maturity levels of the fruits. In all samples, the terpenoids (935.7-1029.74 $\mu \mathrm{g} / \mathrm{g}$ ) followed by aldehydes (68.39-116.4 $\mu \mathrm{g} / \mathrm{g}$ ) were the main components. Terpenes and aldehydes were considered instrumental in the aroma and flavor of orange juice [51]. The results corresponded with those previously reported, wherein the terpenoids were described as the principal group present in herbivore-induced plant volatiles [52].

On day 20 of the storage process, fruits that were kept in a CA2 environment exhibited elevated levels of total terpenoids and aldehydes, while displaying a lower ester amount in comparison to other storage conditions (Table 1). However, fruit that were exposed to RA contained more moderate levels of terpenoids and aldehydes, while the esters and alcohols were significantly higher (Table 1). At the end of the storage period, the terpenoid content in lemons treated with RA, CA1, CA2, CA3, and CA4 were 935.70, 1009.60, 1029.74, 984.17, and $963.56 \mu \mathrm{g} / \mathrm{g}$, respectively. Furthermore, fruit subject to $\mathrm{CA} 2\left(6 \% \mathrm{O}_{2}+8 \% \mathrm{CO}_{2}\right)$ treatment displayed higher terpenoid content than samples subject to other treatments. A major terpenoid compound in lemons is limonene (723.36$741.60 \mu \mathrm{g} / \mathrm{g})$, followed by $\gamma$-Terpinene $(115.56-132.00 \mu \mathrm{g} / \mathrm{g})$ (Table 1). The similar results were obtained by Zhong et al. [12], who reported that d-limonene was far higher than the other free volatile compound and was usually a main compound in lemon, and $\gamma$-Terpinene was the second major compound in Eureka lemon. Terpenoids accounted for the highest concentrations, about 10-, 25-, and 50-fold higher than those of aldehydes, alcohols, and esters, respectively (Table 1). Aldehydes are crucial ester-precursors, since they represent the first step in volatile compound formation [53]. Low levels of esters and alcohols were observed in CA-stored samples, indicating that these compounds were negatively affected by the CA environment.

Recently there are some related reports involving the impact of a CA on the volatile compounds in fruit [6, 54, 55]. Considering 'Royal Gala' apples, research indicated that the emission of straight-chain esters decreased when exposed to extremely low $\mathrm{O}_{2}(0.5 \mathrm{kPa})$, which is related to the aroma [54]. However, studies performed by Matityahu et al. [6] suggested that the levels of ethanol, ethyl acetate, and acetaldehyde in pomegranates increased significantly during a 5-month storage period. Moreover, these volatiles appeared to be higher in a CA environment than when exposed to RA. Additionally, Defilippi et al. [55] reported that, depending on the specific compound, the levels of ethanol, acetaldehyde, and ethyl acetate were 3 to 12 times higher in CA-stored fruit than samples subject to RA. The difference between the research conducted for this paper and similar studies may be due to variations in determination assays and specific fruit cultivars. Results indicated that the CA-stored lemons are characterized by higher terpenoids and aldehydes, while the alcohols and esters remained at lower levels. This is an indication that treatment with a CA can effectively maintain the terpenoids and aldehydes, while negatively impacting the release of esters and alcohols. The CA treatment suppressed the production of ethylene and the rate of respiration. Therefore, since the biosynthesis of the volatile compounds is closely related to the ethylene presence and respiratory activity, the CA-stored fruits contained lower levels of esters and alcohols [9]. In addition, a CA environment characterized by low $\mathrm{O}_{2}$ levels and high $\mathrm{CO}_{2}$ levels successfully inhibited ethylene biosynthesis and activity. This process is crucial for ester forming enzymes to function correctly. Therefore, fruit stored in CA conditions displayed lower ester levels [9]. Although CA treatment negatively affects the ester and alcohol content in lemons, the fact that it efficiently maintains terpenoids, aldehydes, and other vital properties during long-term storage allows for a high-quality product that is acceptable to consumers $[54,56]$.

\section{Conclusion}

The suitable condition of CA system can provide the excellent control on the quality loss of stored fruits. In this works, CA storage of lemon under CA2 $\left(6 \% \mathrm{O}_{2}+8 \% \mathrm{CO}_{2}\right)$ substantially maintained TSS, TA, VC, SSP, and TPC reduced WL and MDA contents. In regard to volatile compounds of lemon, the main volatile compounds consisted of terpenoids, aldehydes, alcohols, and esters. The CA-stored fruits contained lower levels of alcohols and esters, while displaying high retention of terpenoids and aldehydes. Results in this works indicated that the treatment of $\mathrm{CA} 2\left(6 \% \mathrm{O}_{2}+8 \% \mathrm{CO}_{2}\right)$ might provide the optimal storage conditions for the storage of 'Eureka' lemon. Furthermore, the water migration and respiration rate can influence the fruit quality, especially in the longer storage period. The influencing mechanism of CA conditions on the pectin degradation in lemon fruits is also important. Further research works are necessary to conducted in order to understand these issues.

\section{Data Availability}

The data used to support the findings of this study are available from the corresponding author upon request.

\section{Disclosure}

Yuan Ma and Shaohua Li should be regarded as co-first authors.

\section{Conflicts of Interest}

The authors declare that there are no conflicts of interest regarding the publication of this paper.

\section{Authors' Contributions}

Yuan Ma and Shaohua Li contributed to the work equally.

\section{Acknowledgments}

This work was supported by the Chunhui Program Research Project from Ministry of Education of China (Z2017063), Science and Technology Support Program of Sichuan 
(2019NZZJ0028, 2018NZ0090, and 2016FZ0019), Science and Technology Support Program of Yibin (2018ZSF002), Chengdu Science and Technology Project-key Research and Development Program (2018-YF05-00213-SN), Sichuan Provincial Key Laboratory Open Fund Project (GR-2018E-01), Project of Innovation Team Construction Program of Sichuan Education Department (15TD0017), National Natural Science Foundation of China (31501547), and Key Laboratory Open Research Fund of Grain and Oil Processing and Food Safety of Sichuan (szjj2016-024), and Project of Graduate student Innovation Foundation of Xihua University (ycjj2018026). This project is also supported partially by Liying Zhu, from Hangzhou Yishi Science and Technology Co. Ltd., Zhejiang, Hangzhou 310000, China.

\section{References}

[1] J. A. Del Río, M. D. Fuster, P. Gómez, I. Porras, A. GarcíaLidón, and A. Ortuño, "Citrus limon: A source of flavonoids of pharmaceutical interest," Food Chemistry, vol. 84, no. 3, pp. 457-461, 2004.

[2] R. M. Uckoo, G. K. Jayaprakasha, and B. S. Patil, "Phytochemical analysis of organic and conventionally cultivated Meyer lemons (Citrus meyeri Tan.) during refrigerated storage," Journal of Food Composition and Analysis, vol. 42, pp. 63-70, 2015.

[3] R. M. Uckoo, G. K. Jayaprakasha, S. D. Nelson, and B. S. Patil, "Rapid simultaneous determination of amines and organic acids in citrus using high-performance liquid chromatography," Talanta, vol. 83, no. 3, pp. 948-954, 2011.

[4] R. Porat, B. Weiss, L. Cohen, A. Daus, and N. Aharoni, "Reduction of postharvest rind disorders in citrus fruit by modified atmosphere packaging," Postharvest Biology and Technology, vol. 33, no. 1, pp. 35-43, 2004.

[5] P. L. Undurraga, J. A. Olaeta, J. B. Retamales, J. Escobar, and A. M. Toso, "Effect of maturity and storage temperature on the development of peteca in lemons (Citrus limon (L.) Burm. F.) cv. Eureka," Scientia Horticulturae, vol. 122, no. 1, pp. 56-61, 2009.

[6] I. Matityahu, P. Marciano, D. Holland, R. Ben-Arie, and R. Amir, "Differential effects of regular and controlled atmosphere storage on the quality of three cultivars of pomegranate (Punica granatum L.)," Postharvest Biology and Technology, vol. 115, pp. 132-141, 2016.

[7] S. Ali, A. S. Khan, A. U. Malik, and M. Shahid, "Effect of controlled atmosphere storage on pericarp browning, bioactive compounds and antioxidant enzymes of litchi fruits," Food Chemistry, vol. 206, pp. 18-29, 2016.

[8] S.-P. Tian, B.-Q. Li, and Y. Xu, "Effects of $\mathrm{O} 2$ and $\mathrm{CO} 2$ concentrations on physiology and quality of litchi fruit in storage," Food Chemistry, vol. 91, no. 4, pp. 659-663, 2005.

[9] F. R. Thewes, A. Brackmann, R. de Oliveira Anese, E. S. Bronzatto, E. E. Schultz, and R. Wagner, "Dynamic controlled atmosphere storage suppresses metabolism and enhances volatile concentrations of 'Galaxy' apple harvested at three maturity stages,' Postharvest Biology and Technology, vol. 127, pp. 1-13, 2017.

[10] A. Mditshwa, O. A. Fawole, F. Vries, K. van der Merwe, E. Crouch, and U. L. Opara, "Impact of dynamic controlled atmospheres on reactive oxygen species, antioxidant capacity and phytochemical properties of apple peel (cv. Granny Smith)," Scientia Horticulturae, vol. 216, pp. 169-176, 2017.
[11] D. R. Martins and E. D. D. Resende, "External quality and sensory attributes of papaya cv. Golden stored under different controlled atmospheres," Postharvest Biology and Technology, vol. 110, pp. 40-42, 2015.

[12] S. Zhong, J. Ren, D. Chen et al., "Free and bound volatile compounds in juice and peel of Eureka lemon," Food Science and Technology Research, vol. 20, no. 1, pp. 167-174, 2014.

[13] K. Hosni, N. Zahed, R. Chrif et al., "Composition of peel essential oils from four selected Tunisian Citrus species: evidence for the genotypic influence," Food Chemistry, vol. 123, no. 4, pp. 1098-1104, 2010.

[14] X. Feng, Y. Zhu, Q. Liu, S. Lai, and H. Yang, "Effects of Bromelain Tenderisation on Myofibrillar Proteins, Texture and Flavour of Fish Balls Prepared from Golden Pomfret," Food and Bioprocess Technology, vol. 10, no. 10, pp. 1918-1930, 2017.

[15] Y. H. Jo, N. Y. Kim, D. S. An, H. J. Lee, and D. S. Lee, "Modified atmosphere container equipped with gas diffusion tube automaticallycontrolled in response to real-time gas concentration," Biosystems Engineering, vol. 115, no. 3, pp. 250-259, 2013.

[16] A. Bahar and A. Lichter, "Effect of controlled atmosphere on the storage potential of Ottomanit fig fruit," Scientia Horticulturae, vol. 227, pp. 196-201, 2018.

[17] X. Liu, J. Ren, Y. Zhu, W. Han, H. Xuan, and L. Ge, “The preservation effect of ascorbic acid and calcium chloride modified chitosan coating on fresh-cut apples at room temperature," Colloids and Surfaces A: Physicochemical and Engineering Aspects, vol. 502, pp. 102-106, 2016.

[18] D. Ramful, E. Tarnus, O. I. Aruoma, E. Bourdon, and T. Bahorun, "Polyphenol composition, vitamin C content and antioxidant capacity of Mauritian citrus fruit pulps," Food Research International, vol. 44, no. 7, pp. 2088-2099, 2011.

[19] B. Gómez, B. Gullón, R. Yáñez, J. C. Parajó, and J. L. Alonso, "Pectic oligosacharides from lemon peel wastes: Production, purification, and chemical characterization," Journal of Agricultural and Food Chemistry, vol. 61, no. 42, pp. 10043-10053, 2013.

[20] B. Gómez, B. Gullón, R. Yáñez, H. Schols, and J. L. Alonso, "Prebiotic potential of pectins and pectic oligosaccharides derived from lemon peel wastes and sugar beet pulp: A comparative evaluation," Journal of Functional Foods, vol. 20, pp. 108-121, 2016.

[21] L. Zhang, F. Chen, H. Yang et al., "Changes in firmness, pectin content and nanostructure of two crisp peach cultivars after storage," LWT- Food Science and Technology, vol. 43, no. 1, pp. 26-32, 2010.

[22] Y. Xing, X. Li, Q. Xu, J. Yun, Y. Lu, and Y. Tang, "Effects of chitosan coating enriched with cinnamon oil on qualitative properties of sweet pepper (Capsicum annuum L.)," Food Chemistry, vol. 124, no. 4, pp. 1443-1450, 2011.

[23] M. P. de Souza, G. A. Bataglion, F. M. A. da Silva et al., "Phenolic and aroma compositions of pitomba fruit (Talisia esculenta Radlk.) assessed by LC-MS/MS and HS-SPME/GC-MS," Food Research International, vol. 83, pp. 87-94, 2016.

[24] F. Wang, B.-L. Du, Z.-W. Cui, L.-P. Xu, and C.-Y. Li, "Effects of high hydrostatic pressure and thermal processing on bioactive compounds, antioxidant activity, and volatile profile of mulberry juice," Food Science and Technology International, vol. 23, no. 2, pp. 119-127, 2017.

[25] N. Selcuk and M. Erkan, "The effects of modified and palliflex controlled atmosphere storage on postharvest quality and composition of 'Istanbul' medlar fruit," Postharvest Biology and Technology, vol. 99, pp. 9-19, 2015. 
[26] T. Mendy, A. Misran, T. Mahmud, and S. Ismail, "Application of Aloe vera coating delays ripening and extend the shelf life of papaya fruit," Scientia Horticulturae, vol. 246, pp. 769-776, 2019.

[27] Y. Xing, X. Li, Q. Xu, J. Yun, and Y. Lu, "Extending the shelf life of fresh-cut lotus root with antibrowning agents, cinnamon oil fumigation and moderate vacuum packaging," Journal of Food Process Engineering, vol. 35, no. 4, pp. 505-521, 2012.

[28] C. Mannozzi, J. P. Cecchini, U. Tylewicz et al., "Study on the efficacy of edible coatings on quality of blueberry fruits during shelf-life," LWT- Food Science and Technology, vol. 85, pp. 440444, 2017.

[29] Y. Li, L. Zhang, F. Chen, S. Lai, and H. Yang, "Effects of vacuum impregnation with calcium ascorbate and disodium stannous citrate on chinese red bayberry," Food and Bioprocess Technology, vol. 11, no. 7, pp. 1300-1316, 2018.

[30] Y. Xin, F. Chen, S. Lai, and H. Yang, "Influence of chitosanbased coatings on the physicochemical properties and pectin nanostructure of Chinese cherry," Postharvest Biology and Technology, vol. 133, pp. 64-71, 2017.

[31] C. Moggia, R. M. Beaudry, J. B. Retamales, and G. A. Lobos, "Variation in the impact of stem scar and cuticle on water loss in highbush blueberry fruit argue for the use of water permeance as a selection criterion in breeding," Postharvest Biology and Technology, vol. 132, pp. 88-96, 2017.

[32] L. Zhang, S. Zhao, S. Lai, F. Chen, and H. Yang, "Combined effects of ultrasound and calcium on the chelate-soluble pectin and quality of strawberries during storage," Carbohydrate Polymers, vol. 200, pp. 427-435, 2018.

[33] D. Sivakumar and L. Korsten, "Fruit quality and physiological responses of litchi cultivar McLean's Red to 1methylcyclopropene pre-treatment and controlled atmosphere storage conditions," LWT- Food Science and Technology, vol. 43, no. 6, pp. 942-948, 2010.

[34] K. Barman, M. W. Siddiqui, V. B. Patel, and M. Prasad, "Nitric oxide reduces pericarp browning and preserves bioactive antioxidants in litchi," Scientia Horticulturae, vol. 171, pp. 71-77, 2014.

[35] H. Liu, F. Chen, H. Yang et al., "Effect of calcium treatment on nanostructure of chelate-soluble pectin and physicochemical and textural properties of apricot fruits," Food Research International, vol. 42, no. 8, pp. 1131-1140, 2009.

[36] S. Supapvanich, J. Pimsaga, and P. Srisujan, "Physicochemical changes in fresh-cut wax apple (Syzygium samarangenese [Blume] Merrill \& L.M. Perry) during storage," Food Chemistry, vol. 127, no. 3, pp. 912-917, 2011.

[37] Q. Xu, Y. Xing, Z. Che et al., "Effect of chtiosan coating and oil fumigation on the microbiological and quality safety of freshcut pear," Journal of Food Safety, vol. 33, no. 2, pp. 179-189, 2013.

[38] P. V. Mahajan and T. K. Goswami, "Extended storage life of litchi fruit using controlled atmosphere and low temperature," Journal of Food Processing and Preservation, vol. 28, no. 5, pp. 388-403, 2004.

[39] Y. Xing, X. Li, Q. Xu, Y. Jiang, J. Yun, and W. Li, "Effects of chitosan-based coating and modified atmosphere packaging (MAP) on browning and shelf life of fresh-cut lotus root (Nelumbo nucifera Gaerth)," Innovative Food Science and Emerging Technologies, vol. 11, no. 4, pp. 684-689, 2010.

[40] A. Mditshwa, O. A. Fawole, F. Vries, K. van der Merwe, E. Crouch, and U. L. Opara, "Minimum exposure period for dynamic controlled atmospheres to control superficial scald in 'Granny Smith' apples for long distance supply chains," Postharvest Biology and Technology, vol. 127, pp. 27-34, 2017.
[41] S.-P. Tian, A.-L. Jiang, Y. Xu, and Y.-S. Wang, "Responses of physiology and quality of sweet cherry fruit to different atmospheres in storage," Food Chemistry, vol. 87, no. 1, pp. 4349, 2004.

[42] O. A. Fawole and U. L. Opara, "Harvest discrimination of pomegranate fruit: Postharvest quality changes and relationships between instrumental and sensory attributes during shelf life," Journal of Food Science, vol. 78, no. 8, pp. S1264-S1272, 2013.

[43] H. Yang, Q. Wu, L. Y. Ng, and S. Wang, "Effects of Vacuum Impregnation with Calcium Lactate and Pectin Methylesterase on Quality Attributes and Chelate-Soluble Pectin Morphology of Fresh-Cut Papayas," Food and Bioprocess Technology, vol. 10, no. 5, pp. 901-913, 2017.

[44] H. Liu, F. Chen, S. Lai, J. Tao, H. Yang, and Z. Jiao, "Effects of calcium treatment and low temperature storage on cell wall polysaccharide nanostructures and quality of postharvest apricot (Prunus armeniaca)," Food Chemistry, vol. 225, pp. 8797, 2017.

[45] Q. Liu, C. S. Cedric Tan, H. Yang, and S. Wang, "Treatment with low-concentration acidic electrolysed water combined with mild heat to sanitise fresh organic broccoli (Brassica oleracea)," LWT_Food Science and Technology, vol. 79, pp. 594-600, 2017.

[46] H.-S. Yang, G.-P. Feng, H.-J. An, and Y.-F. Li, "Microstructure changes of sodium carbonate-soluble pectin of peach by AFM during controlled atmosphere storage," Food Chemistry, vol. 94, no. 2, pp. 179-192, 2006.

[47] S. Huyskens-Keil, H. Prono-Widayat, P. Lüdders, and M. Schreiner, "Postharvest quality of pepino (Solanum muricatum Ait.) fruit in controlled atmosphere storage," Journal of Food Engineering, vol. 77, no. 3, pp. 628-634, 2006.

[48] H. Yang, S. Lai, H. An, and Y. Li, "Atomic force microscopy study of the ultrastructural changes of chelate-soluble pectin in peaches under controlled atmosphere storage," Postharvest Biology and Technology, vol. 39, no. 1, pp. 75-83, 2006.

[49] B. Rubio, C. Vieira, and B. Martínez, "Effect of post mortem temperatures and modified atmospheres packaging on shelf life of suckling lamb meat," LWT- Food Science and Technology, vol. 69, pp. 563-569, 2016.

[50] C.-W. Liu, K.-H. Lin, and Y.-M. Kuo, "Application of factor analysis in the assessment of groundwater quality in a blackfoot disease area in Taiwan," Science of the Total Environment, vol. 313, no. 1-3, pp. 77-89, 2003.

[51] A. Plotto, C. A. Margaría, K. L. Goodner, R. Goodrich, and E. A. Baldwin, "Odour and flavour thresholds for key aroma components in an orange juice matrix: Terpenes and aldehydes," Flavour and Fragrance Journal, vol. 19, no. 6, pp. 491-498, 2004.

[52] A. Mithöfer and W. Boland, "Plant defense against herbivores: Chemical aspects," Annual Review of Plant Biology, vol. 63, pp. 431-450, 2012.

[53] F. R. Thewes, V. Both, A. Brackmann, D. D. F. Ferreira, and R. Wagner, "1-methylcyclopropene effects on volatile profile and quality of 'Royal Gala' apples produced in Southern Brazil and stored in controlled atmosphere," Ciência Rural, vol. 45, no. 12, pp. 2259-2266, 2015.

[54] V. Both, A. Brackmann, F. R. Thewes, D. D. F. Ferreira, and R. Wagner, "Effect of storage under extremely low oxygen on the volatile composition of 'Royal Gala' apples," Food Chemistry, vol. 156, pp. 50-57, 2014.

[55] B. G. Defilippi, B. D. Whitaker, B. M. Hess-Pierce, and A. A. Kader, "Development and control of scald on wonderful pomegranates during long-term storage," Postharvest Biology and Technology, vol. 41, no. 3, pp. 234-243, 2006. 
[56] M. L. López, C. Villatoro, T. Fuentes, J. Graell, I. Lara, and G. Echeverría, "Volatile compounds, quality parameters and consumer acceptance of 'Pink Lady(R)' apples stored in different conditions," Postharvest Biology and Technology, vol. 43, no. 1, pp. 55-66, 2007. 


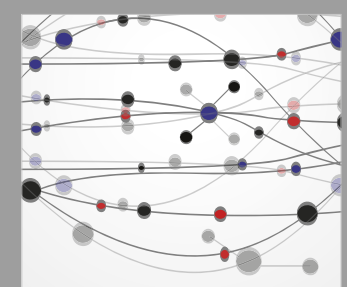

The Scientific World Journal
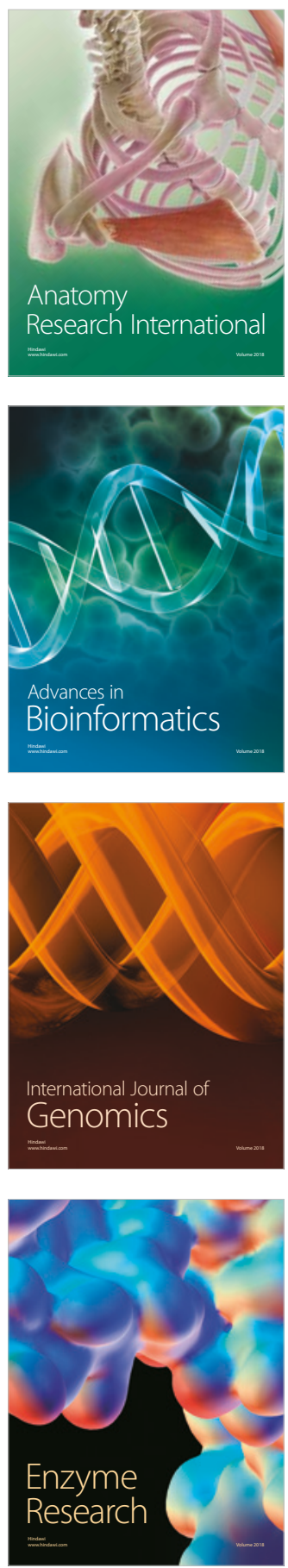


Submit your manuscripts at

www.hindawi.com
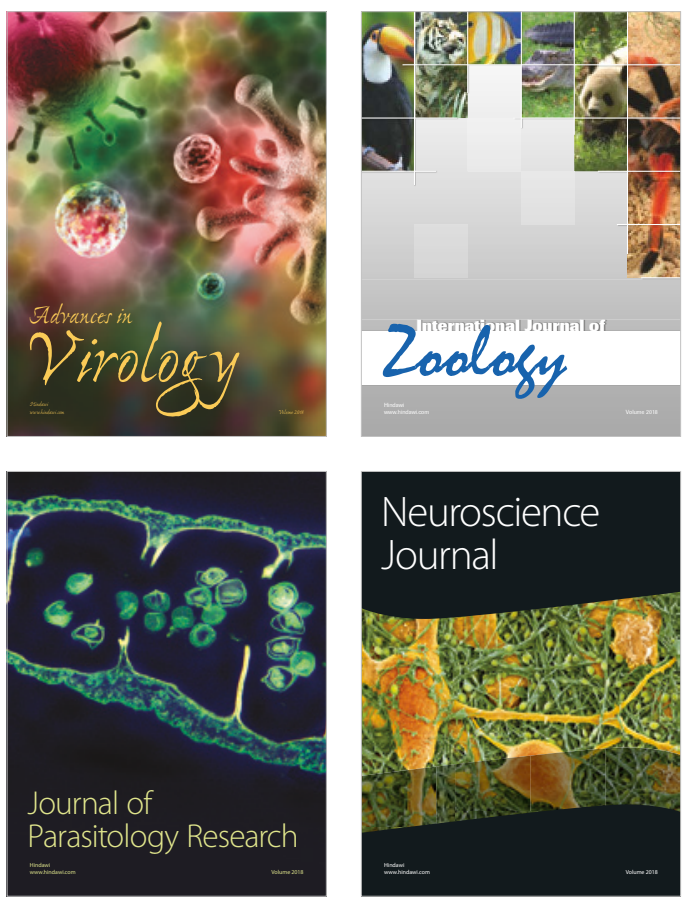
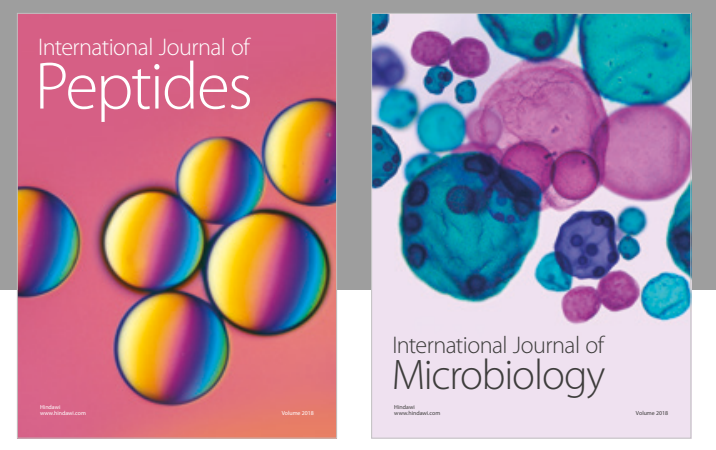

nternational Journal of Microbiology
Journal of
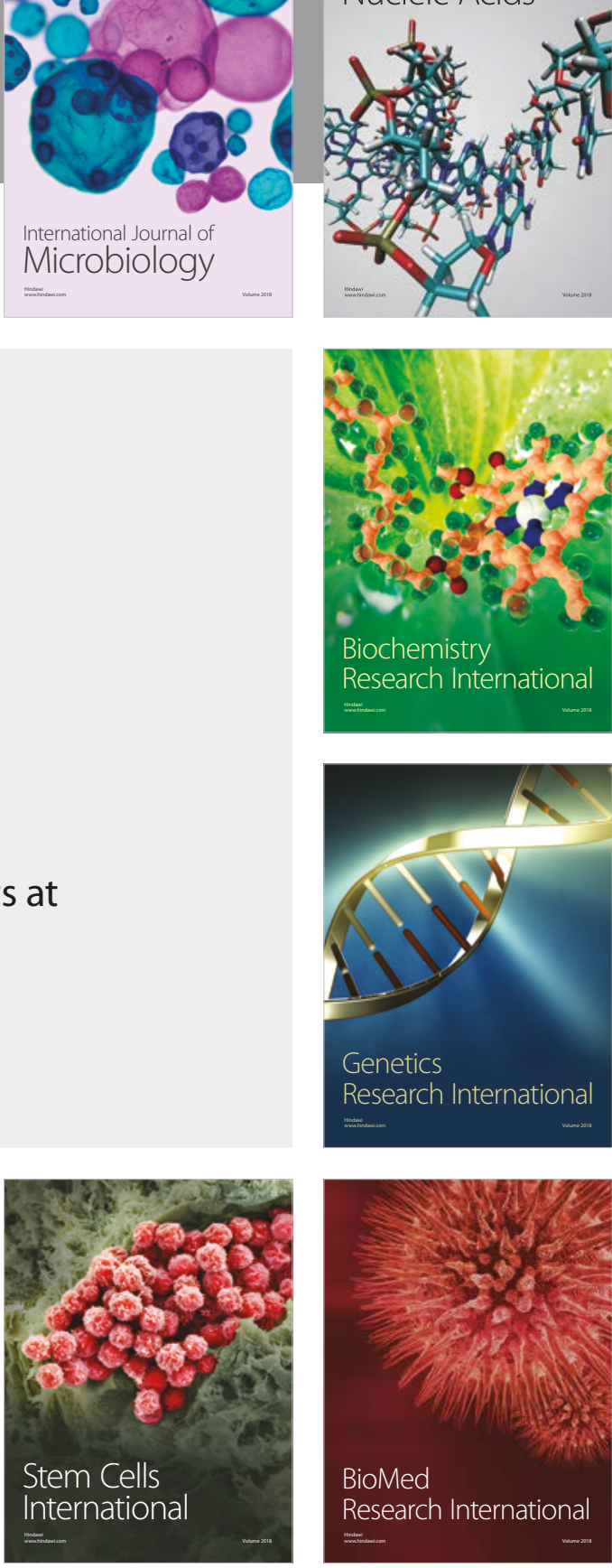
